\title{
Spatial Econometric Models and The Analysis of the Determinants of Internal Migration in Turkey
}

\author{
Suna Tatı* $\odot$, Ferda Yerdelen Tatoğlư
}

\begin{abstract}
Spatial econometric models have become increasingly popular in economic studies, especially in recent years. These models differ from classical econometric models in that they take into account the effects arising from the location of the data set subject to the study. The spatial effect seen in a data set comes in two forms. The first form is spatial autocorrelation, which is defined as the correlation between neighboring locations. The other form is spatial heterogeneity, defined as the variance of a variable under consideration from place to place. The aim of this study was to find out whether the factors affecting provincial migration in Turkey have spatial characteristics. For this purpose, data from 2014 were selected as all data were accessible. A coherence matrix was constructed by considering the borders of the provinces to show the possible spatial relationship and this matrix was used in the econometric models. The distribution map of migration by province was examined and it was found that there was significant clustering, especially towards the northeast-southwest. From this point of view, the provinces where the spatial effect was significant in the clustered regions were identified using LISA statistics. The spatial model was determined in accordance with the orientation of the factors affecting migration and the movement of these variables was evaluated based on the provinces with significant correlation. The results obtained fit with the economic theory.
\end{abstract}

Keywords

Migration, Spatial Econometrics, Spatial Autocorrelation, Spatial Autoregressive Model

* Corresponding author: Suna Tatlı (Lecturer), Istanbul Rumeli University, Vocational School of Health Services, Department of Medical Services and Techniques, Istanbul, Turkey. E-mail: suna.tatli@rumeli.edu.tr ORCID: 0000-0002-9894-934X

** Ferda Yerdelen Tatoğlu (Prof. Dr.), Istanbul University, Faculty of Economics Department of Econometrics, Istanbul, Turkey. E-mail: yerdelen@istanbul.edu.tr ORCID: 0000-0002-7365-3649

To cite this article: Tatli, S., \& Yerdelen Tatoglu, F. (2021). Spatial Econometric Models and The Analysis of the Determinants of Internal Migration in Turkey. EKOIST Journal of Econometrics and Statistics, Advanced online publication. https://doi.org/10.26650/ekoist.2022.36.995797 


\section{Introduction}

Spatial econometrics is a subdiscipline of econometrics that deals with the combination of econometric methods and spatial effects. The main focus of this branch of science is on spatial effects, which reveal the relational structure between spaces. The spatial effect, expressed as the interaction between spaces, can cause spatial dependence. Spatial dependence is a special case of cross-sectional dependence, or spatial heterogeneity, which is a special case of cross-sectional heterogeneity. The dependency structure can be related to distance and location, and this structure can be seen in a geographical area and an economic or social network (Anselin, Le Gallo, and Jayet, 2008: 625). From this point of view, the spatial econometric models can also be used to explain the behaviour of socio-economic entities such as individuals, firms, or governments that are not geographical entities.

The distinction between spatial econometrics and traditional econometrics can be viewed in two different ways. The first focuses on the subject. Accordingly, the statistical analysis of regional science-related economic models falls within the domain of spatial econometrics. In this context, studies such as the estimation of the spatial interaction model, the statistical analysis of the urban density function, and the empirical analysis of the regional econometric models can be considered within the scope of spatial econometrics (Anselin, 1988: 8).

The second approach operates within a narrower framework and is concerned with the specific spatial effects of regional science data and models that standard econometric methods cannot directly resolve. These effects are of two types: a) spatial dependence and b) spatial heterogeneity. In particular, since the seminal work of Cliff and Ord (1973), spatial dependence can also be referred to as spatial autocorrelation, the best known and widely recognised effect. This effect is often used to refer to the dependence between observations in a cross-sectional data set. According to Waldo Tobler (1979), this dependence is expressed by the first law of geography: "Everything is related to everything else, but near things are more related than distant things." (Anselin, 1988: 8). In this context, spatial dependence means that the value of a variable in one place depends not only on internal conditions but also on the value of the same variable in neighbouring places (Frexedas and Faya, 2005: 154).

The correlation between locations $i$ and $j$ can be represented as follows:

$$
\operatorname{Cov}\left(y_{i}, y_{j}\right)=E\left(y_{i}, y_{j}\right)-E\left(y_{i}\right) E\left(y_{j}\right) \neq 0 \quad \forall_{i} \neq j
$$

Here, the correlation between the location $i$ and $j$ is non-zero, that is, the locations are spatially related.

In a broader sense, spatial autocorrelation can be defined as the harmony of value similarity and location similarity (Viton, 2010: 3). This harmony can be observed 
both positively and negatively due to the nature of autocorrelation. If the selection of spatial units is random, there is no harmony; in other words, there can be no spatial autocorrelation. Positive spatial autocorrelation can be defined when low or high values for a random variable tend to cluster in an area. In contrast, negative spatial autocorrelation can be defined when very different values from neighbouring locations surround a location.

Of these two cases of spatial autocorrelation, positive autocorrelation is more likely to occur, while negative spatial autocorrelation may not always give comprehensible and easily interpretable results (Viton, 2010: 3).

The second type of spatial effect is spatial heterogeneity. Spatial heterogeneity means that the functional form and parameters vary by location within the data but are not homogeneous. In contrast to the spatial dependence case, classical econometric techniques are used to solve problems arising from spatial heterogeneity (Anselin, 1988: 9).

The term spatial heterogeneity refers to a change in relationships in an area. Econometrically, it is the observation of a different relationship at each point in an area (Lesage, 1999: 7). It can be expressed as instability of the coefficients or residual variance of the model and it causes spatial units to move away from homogeneity. Spatial heterogeneity can cause the residual variance of the model to vary across the different spatial groups considered, in other words, heteroskedasticity. Moreover, neglected variables, incorrect determination of the model specification, and measurement errors can also lead to heteroscedasticity. In this case, techniques that consider structural change, such as heterogeneous models or random coefficient models, switching regression can be used in econometric studies (Anselin, 1988: 13).

Spatial heterogeneity can be represented in a linear regression model as follows,

$$
y_{i}=f_{i}\left(x_{i} \beta_{i}, \varepsilon_{i}\right)
$$

or

$$
y_{i}=x_{i} \beta_{i}+\varepsilon_{i}
$$

Here, $i$ refers to the observations collected from the points in the field, $i=1,2, \ldots, n$ (Lesage, 1999:7). $x_{i}$ is the (1xk) dimensional matrix of explanatory variables and $y_{i}$ is the dependent variable vector. Where $\beta_{i}$ is the parameter vector, $\varepsilon_{i}$ represents a stochastic disorder in the linear relationship; in other words, the error term.

A matrix constructed by various methods can reveal the relational structure resulting from the location between regions or units considered in spatial econometrics. Geographical weighting techniques are used when the units in question are treated according to their geographical location. In contrast, socio-economic weighting 
techniques can be used when they are to be treated according to the relational structure and interaction between them. The aim of all these techniques is to show how the links between units are realised. In this study, among the geographical weighting techniques, weighting based on coherence was used.

This is the determination of the boundaries of the relationship between spatial units based on their location on a distinguishable map. Areas with common boundaries and surrounding areas can be weighted in many ways. Depending on the common edges and corners shared by said spaces, three neighbourhood definitions have been developed that resemble movements on the chessboard. These are in the form of a rook, bishop, and queen neighbourhood (Gumprecht, 2007: 6). If adjacent spaces share an edge, it is a rook neighbourhood; if adjacent spaces share a corner, it is a bishop neighbourhood; if adjacent spaces share an edge and corner, it is a queen neighbourhood.

A spatial neighbourhood matrix is a $N x N$ positive matrix $\widetilde{W}$. The $\widetilde{w}_{\mathrm{ij}}$ element of the matrix represents the strength of the interaction between the row element of the matrix, the location $i$, and the column element, the location $j$. The strength of the relationship between these observations can be represented and interpreted by a network such as the spatial weight structure. In the simplest terms, the neighbourhood matrix takes a binary value, locations $i$ and $j$ take the value $\widetilde{w}_{\mathrm{ij}}=1$ if they are neighbours and $\widetilde{w}_{\mathrm{ij}}=0$ if they are not. These are the diagonal elements of the matrix $\widetilde{w}_{\mathrm{ij}}=0$ (Anselin et al., 2008: 627).

The most basic tool for testing and measuring the spatial autocorrelation level is the Moran I-statistic developed by Moran. The Moran I statistic measures the strength of spatial autocorrelation that occurs in a spatial stochastic process (Gumprecht, 2007: 15). This measurement can be made visually using the Moran I scatter diagram or by testing hypotheses with the Moran I test. Although there are statistics such as Geary C (1954) and Getis \& Ord G (1992) to perform this measurement, the most preferred method in practise is to use the Moran I statistic.

The differentiation of the relational structures observed in the data has led to the development of different spatial model specifications (Fischer and Wang, 2011: 32). All linear spatial econometric models between the non-spatial model and the Manski model, which is the most comprehensive spatial model, are summarized in Figure 1. To the right of the Manski model, any model is obtained by applying one or more restrictions to its parameters (Elhorst, 2010: 11). 


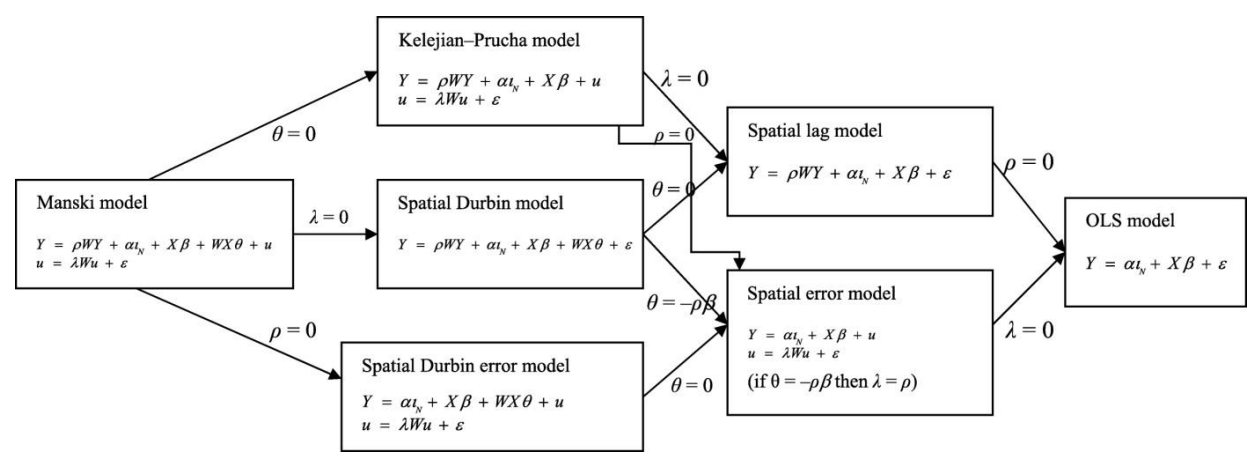

Figure 1. Spatial Regression Models (Elhorst, 2010: 13)

\section{Literature}

\section{Literature Review}

Since the early 1970s, there have been many studies dealing with the migration problem in Turkey. This phenomenon has attracted the attention of both foreign and domestic researchers. In this context, the most important studies that have been carried out so far on the phenomenon of migration are the following:

In the study conducted by John M. Munro (1974), a model was set up in a driving forces to determine what factors influenced internal migration in Turkey between the years 1960-1965. In the study conducted by Rainer Doh (1984), the aim was to determine the socio-economic factors affecting inter-provincial migration in Turkey and according to the results, a significant relationship was found between employment opportunities and migration rates. Tunali (1996), in his study, examined the factors influencing migration and reverse migration, decisions of individuals between the years 1963-1973 in Turkey. As a result of this research, it was found that return migration is a negative experience for most immigrants.

Yamak and Yamak (1999) empirically investigated the relationship between interprovincial net migration and per capita income during the years 1980-1990. They examined how much of the total population migrated for economic reasons, how this relationship affected regional income imbalances and the impact of income imbalances on internal migration. They concluded that the effect of income imbalances on migration was due more to the high-income levels of provinces receiving immigration than to the low-income levels of provinces sending out migrants. In other words, they emphasised that pull factors rather than push factors influence migration more.

In his study, Pazarlioglu (2007) used panel data models to examine internal migration in Turkey. For this purpose, he developed two scenario analyses and made estimations about internal migration using appropriate models. As a result of the 
created scenarios and models, it was found that the most effective means to prevent internal migration is to eliminate inequality in income distribution and to eliminate economic disparities between cities, and it was found that one of the most important consequences of internal migration is unplanned urbanisation.

In their study, Ercilasun, Hic Gencer and Ersin (2011) estimated the factors determining internal migration in Turkey based on provinces using the least squares method. The most striking result of this study is that the most important factor affecting the internal migration decisions of individuals in Turkey is the attraction of those who have already migrated. The significance of the autoregressive models, in which net migration and net migration rate are affected by their own lagged values, supports this situation. Another important finding of the study is that individuals base their migration decisions on the high capacity of universities in the provinces.

These studies, which aim to uncover the determinants of migration for Turkey, have shown that in addition to socioeconomic pull factors such as employment, education, and relatives who have previously settled in the migrated place, push factors such as security problems, unemployment, and underdevelopment also influence internal migration. It has also been proven that the Marmara, Aegean, Western Anatolia and Mediterranean regions of Turkey are immigrant-receiving regions, and the regions other than these are regions of emigration. Recently, the phenomenon of migration has also been studied using spatial econometric techniques. Major works are:

Abar(2011) attempted to explain inter-province migration using spatial econometric techniques using matrices of in-migration and out-migration characteristics, drawing on 2009 migration statistics. The model used representative variables for economic indicators and employment opportunities, representative variables, elitism variables, distance, and stock migration variables for social incentives and environmental factors. First, border neighbourhood matrices of the origin and destination provinces were constructed, and spatial models were estimated using these matrices. As a result of the model estimation, it was found that the most important variable that effectively explains migration is income inequality. In addition, the effect of education on migration was examined in the elitism variable group, and it was concluded that the high proportion of individuals with elite characteristics in the province that granted immigration increased the migration rates of that province. The level of social welfare in the province to be immigrated to is also an attractive factor for migration. Considering that high stock migration increases the likelihood of having more acquaintances and relatives in the immigrating province, it can be seen that having acquaintances and relatives in the immigrating province is also a factor that increases migration. The costs incurred in migration are also factors that influence migration. These costs generally increase as the distance between provinces increases. When examining the model results, it can be seen that the increase in distance between 
provinces has a reducing effect on migration. This result supports other studies in the literature; therefore, spatial effects were found in the migration data in parallel with the expectations.

In his study, Yakar (2012) conducted a spatial analysis of internal migration by district in Turkey for the period of 1995-2000. The fact that the study was conducted at the district level obviously revealed differences within the province. When examining the distribution of migration efficiency and mobility rates, it can be seen that west of the Adana-Zonguldak line the mobility level is high and migration is crucial for population growth, while east of this line the mobility level remains at a lower level and the effect of migration on population growth is limited.

Our article was derived from a thesis written in 2016. Since the completion of the thesis, which laid the groundwork for this study, studies examining the variables on a provincial basis with spatial econometric techniques have gained momentum. Some of the current studies on migration with spatial econometrics technique are as follows:

Anavatan (2017) used the spatial error model to find the determinants of provincial internal migration in Turkey in 2015. According to the results of this study, agricultural lands and crime rates negatively affect net migration. In addition, it was concluded that net migration increased as the level of education, wealth, industry, tourism and trade in society increased.

Ozdemir (2018) aimed to find the determinants of the net migration rate for 26 subregions of Turkey between 2008 and 2016. According to analysis results, the most important variables affecting interregional migration have been found to be education, regional wealth, per capita electricity consumption, urbanization and terrorism.

In their study, Ozkubat and Selim (2019) examined various economic, physical and social indicators of the provinces between the years 2008-2015 in Turkey, in order to quantify the developmental differences between the provinces with spatial econometric techniques. As a result of the spatial analysis, they concluded that an increase in the development level of a province will not only increase the development index of that province, but will also increase the development indexes of the surrounding provinces.

Ondes and Kizilgol (2020) examined the effects of variables on internal migration between 2008-2017 with spatial panel data models. For this purpose, they divided the factors affecting the migration movement into two groups, push and pull factors. As a result, unemployment, imports and per capita income were determined to be push factors. As the per capita income in the region is above the Turkey average, the employment growth and the diversity of agricultural areas were found to be pull factors. 


\section{Contribution to the Literature}

When examining the literature on spatial econometrics in Turkey, one finds that studies in this field have increased in the last 10 years but have not reached the desired level. The number of studies that fully present spatial econometric theory and its applications is quite limited, especially at the time of this study. This study contributes to the literature, especially in the context of the introduction of spatial econometric theory and spatial econometric models, and as it explains the factors affecting internal migration from the year it covers.

\section{DATA AND MODEL}

In this study, spatial econometric analysis is conducted to explain the determinants of migration in provinces in Turkey, based on the data published by the Turkish Statistical Institute (TUIK). Due to the fact that the unit size is provinces and there are possible neighbourhood relations between provinces, spatial correlation can be seen between the residuals. When trying to reveal the factors causing migration in the econometric model to be established, econometric estimations will be made with the help of methods that also take into account spatial correlations. The variables and variable transformations used for this purpose are as follows:

Table 1

Variables Used in the Model

\begin{tabular}{ll}
\hline LNMIG & Logarithm of outgoing migration \\
MAR & Marriage rate \\
DIV & Divorce rate \\
LNBIRTH & Logarithm of the number of births \\
LNAGR & Logarithm of agricultural area (hectares) \\
LNHONEY & Logarithm of honey production (tonnes) \\
LNGRAD & Logarithm of the number of university graduates \\
UNI & Number of universities \\
\hline
\end{tabular}

The data used in the study were compiled from the statistics of TUIK, focusing on the year 2014 as all the data was accessible. The data from TUIK statistics were used to build the spatial econometric model, and the analyses were carried out using the statistical and econometric package programmes Stata and GeoDa.

The map of the spatial distribution of migration by province is shown in Figure 1. This map provides a priori information on whether the data have a spatial effect or not. The map of spatial distribution can be used to investigate whether the distribution of the given migration is random, or in other words, the spatial dependence of migration. 


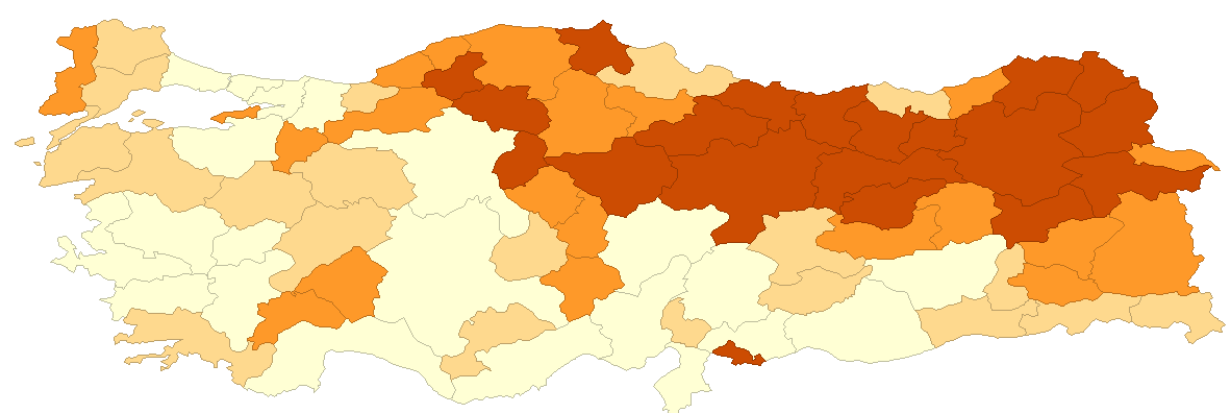

Figure 2. Spatial Distribution Map of Outgoing Migration

An examination of the spatial distribution of the given migration shows that the data distribution is not random and has a systematic distribution, especially in the northeast-southwest line. The provinces in bold are the provinces with the highest number of immigrants.

The distribution map shows the distribution of all data in each location. In which regions this distribution is significant and in which regions it is not can be checked with the LISA statistics mentioned earlier. In this context, the LISA map obtained for the migration variable is as follows:

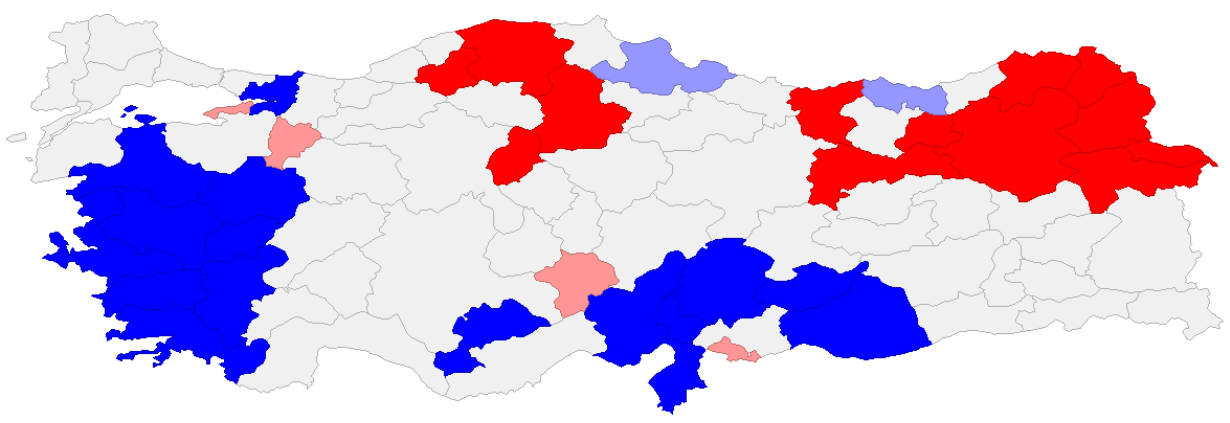

Figure 3. LISA Map of Outgoing Migration

The areas marked in white on the LISA map are the areas of high migration, but the migration is not due to the spatial effect. To put it more clearly, there is no significant correlation between these provinces due to their location.

The areas marked in red on the LISA map represent the provinces that are the 1st region in the Moran I scatter plot and fall in the area where the relationship is highhigh, showing spatial clustering. The high-high correlation indicates that the rate of emigration is high in these regions and it is also high in neighbouring regions. 
The areas marked in pink on the LISA map represent the provinces that are the 4th region in the Moran I scatter plot, which shows the spatial extreme value and represent areas where the relationship is high-low. The high-low correlation indicates that emigration is high in these regions and low in neighbouring regions.

The blue highlighted areas on the LISA map represent the provinces that are the 3rd region in the Moran I scatter plot and show the spatial clustering that falls in the area where the relationship is low-to-low. The low-low relationship indicates that the emigration in these regions is low and it is also low in neighbouring regions.

The areas marked in dark blue on the LISA map represent the provinces that are the 2 nd region in the Moran I scatter plot, have the spatial extreme value and fall in the area where the relationship is low-high. The low-high correlation indicates that emigration is low in these regions and is high in the neighbouring regions.

Considering all this information, the summary of significant correlations in the LISA map is as follows:

Table 2

LISA Map Summary Table

\begin{tabular}{cccc}
\hline High - High & High - Low & Low - Low & Low - High \\
\hline Erzurum, Igdir & & & Kutahya, Denizli \\
Kars, Artvin & & & Sanliurfa, Izmir \\
Kastamonu, Corum & Yalova, Nigde & Samsun & Manisa, Mugla \\
Agri, Bayburt & Bilecik, Kilis & Trabzon & Aydin, Kocaeli \\
Ardahan, Kirikkale & & & Usak, Balikesir \\
Karabuk, Giresun & & & Adiyaman, Adana \\
Erzincan & & Kahramanmaras, Hatay \\
& & Osmaniye, Karaman \\
\hline
\end{tabular}

Examining the provinces where the correlation is significant, we find a significant clustering, especially in the northeast-southwest line.

The Moran I scatter plot, which geometrically represents the spatial autocorrelation, is as follows:

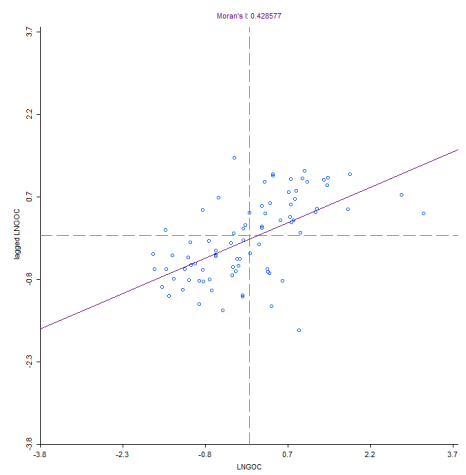

Figure 4. Moran I Scatter Plot 
Looking at the scatter plot created for the migration, we find that the dependent variable has a significant positive spatial autocorrelation a priori. However, a significance test should be performed for the final result. The significance of the Moran I statistic can be examined as follows:

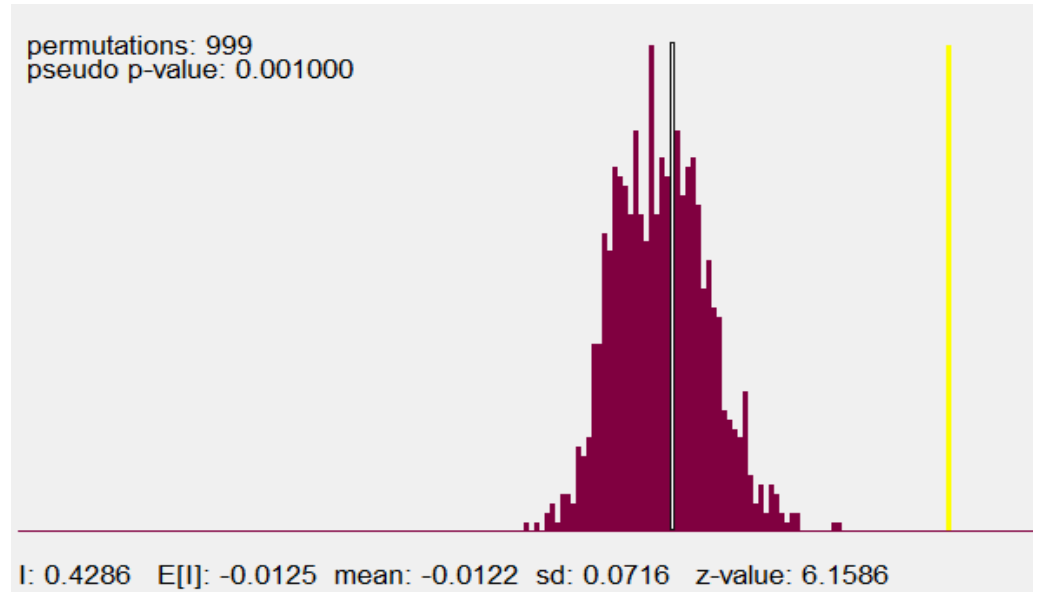

Figure 5. Significance Test of Moran I Statistics

At the bottom of the figure above, the Moran I statistic $I=0.4286$, the expected value $E(I)=-0.0125$, average (-0.0122), and $z$ statistic (6.1586) are shown, respectively. When the

\section{$H_{0}:$ There is no spatial autocorrelation}

\section{$H_{A}:$ There is spatial autocorrelation}

hypotheses are tested at the 5\% significance level, since the (pseudo-p-value) is $0.001<0.05$ the $H_{0}$ hypothesis is rejected; in other words, there is spatial autocorrelation. The value of the Moran I statistic is examined to determine the direction of autocorrelation (positive or negative). In the analysis, a value of approximately 0.43 was determined. A positive value indicates the presence of a positive autocorrelation. Therefore, migration between provinces has a positive spatial structure.

The diagnostic tests to determine the spatial model accurately reflect that the relationship structure is based on Ordinary Least Squares (OLS) residuals. For this reason, the OLS model was used first. 
Table 3

Ordinary Least Square Estimation Results

\begin{tabular}{lcccc}
\hline \multicolumn{1}{c}{ Variable } & Coefficient & Standard Error & $\boldsymbol{t}$ & Probability \\
\hline \multirow{2}{*}{ Fixed Term } & & Dependent variable: LNMIG & & \\
MAR & 4.500029 & .7118038 & 6.32 & 0.000 \\
DIV & .0608362 & .0260062 & 2.34 & 0.000 \\
LNBIRTH & -.2325384 & .036311 & -6.40 & 0.000 \\
LNHONEY & -.2895268 & .0293724 & -9.86 & 0.000 \\
LNGRAD & .0536381 & .0203765 & 2.63 & 0.010 \\
LNAGR & .3725379 & .1618858 & 2.30 & 0.024 \\
UNI & .0443298 & .0182469 & 2.43 & 0.018 \\
\hline
\end{tabular}

$\mathrm{R}^{2}: 0.7762$

Adjusted $\mathrm{R}^{2}: 0.7547$

F: 36.17

In order to determine the effect of the observed spatial structure, diagnostic tests were performed using the residuals of the model given in Table 3 . The test results of the application are summarized in the table below:

Table 4

Diagnostic Test Results

\begin{tabular}{ccc}
\hline Test & Coefficient & Probability \\
\hline Moran I(error) & 2.6480 & 0.00810 \\
$L M_{\rho \lambda}$ & 14.1322 & 0.00085 \\
$L M_{\rho}$ & 14.0877 & 0.00017 \\
Robust LM $_{\rho}$ & 10.6909 & 0.00108 \\
$L M_{\lambda}$ & 3.4414 & 0.06358 \\
Robust LM & 0.0445 & 0.83291 \\
\hline
\end{tabular}

Among the tests used to decide on the appropriate dependency structure, $L M \rho$ is used to test spatial autoregression dependence, $L M_{\lambda}$ spatial error dependence, and $L M \rho \lambda$, the most general form of these two tests, is used to test whether both dependencies coexist. First of all, the test, which is expressed with $L M \rho_{\lambda}$ and whose hypotheses are:

$$
\begin{aligned}
& H_{0}: \rho=\lambda=0 \\
& H_{A}: \rho \neq \lambda \neq 0
\end{aligned}
$$

should be applied. Based on the test results, the $H_{0}$ hypothesis is rejected at the $95 \%$ confidence level. In this case, the effects should be tested individually. The hypotheses of the test expressed by $L M \rho$ that tests the spatial autoregression dependency are as follows:

$$
\begin{aligned}
& H_{0}: \rho=0 \\
& H_{A}: \rho \neq 0
\end{aligned}
$$


An examination of the $L M \rho$ results shows that the classical regression assumption with a $5 \%$ margin of error is not valid; therefore, there is a spatial autoregression effect. The hypotheses of the test expressed by $L M_{\lambda}$, which tests spatial error dependence, are as follows:

$$
\begin{aligned}
& H_{0}: \lambda=0 \\
& H_{A}: \lambda \neq 0
\end{aligned}
$$

An examination of the $L M_{\lambda}$ results at the $95 \%$ confidence level are examined shows that the classical regression assumption is valid and that there is no spatial error effect. When both effects are significant, resistant statistics are used to determine the appropriate model. In practice, if one effect is significant and the other is not, it is not necessary to evaluate resistant statistics. In the light of all these results, it can be understood that the spatial autoregression effect exists, and that the spatial error effect does not exist. Therefore, the appropriate spatial model is the spatial autoregressive model (SAR Model). The results of the spatial autoregressive model $(S A R)$ are summarized in the table below.

Table 5

SAR Model Results

\begin{tabular}{lcccc}
\hline \multicolumn{1}{c}{ Variable } & Coefficient & Standard Error & $\boldsymbol{z}$ & Probability \\
\hline Dependent variable: LNMIG & & & \\
W_LNMIG $(\rho)$ & 0.2719618 & 0.07847725 & 3.465486 & 0.00053 \\
Fixed Term & 3.308441 & 0.7006369 & 4.722048 & 0.00000 \\
MAR & 0.07220222 & 0.02297509 & 3.142631 & 0.00167 \\
DIV & -0.1848704 & 0.03509348 & -5.267942 & 0.00000 \\
LNBIRTH & -0.2691164 & 0.02594943 & -10.3708 & 0.00000 \\
LNHONEY & 0.05102117 & 0.01779598 & 2.867005 & 0.00414 \\
LNGRAD & 0.3319331 & 0.1421596 & 2.334933 & 0.01955 \\
LNAGR & 0.04240841 & 0.01593481 & 2.661368 & 0.00778 \\
UNI & 0.01721237 & 0.003722697 & 4.623629 & 0.00000 \\
\hline
\end{tabular}

$\mathrm{R}^{2}=0.810623$

An examination of the model results in the table shows that all variables are statistically significant at the $95 \%$ confidence level. The coefficient of significance $\left(R^{2}\right)$ is $0.81 . \rho$, which is an indicator of spatial dependence, is also significant at the $95 \%$ confidence level. The fact that the spatial autoregression term $\rho$ is positive indicates that the direction of migration in an area will be the same direction in neighboring regions; therefore, the immigration rate for each province is affected by all these variables, as well as by the immigration in neighbouring provinces.

\section{Findings}

According to the research, every $1 \%$ increase in the marriage rate increases the migration rate by $7.22 \%$. The positive relationship between the marriage rate and the 
migration rate is also confirmed in the literature. Ozgur and Aydin (2011) examined the effect of marriage on migration using spatial econometric techniques, with the distinction between males and females, and concluded that there is a positive spatial autocorrelation between migration and marriage. The results in this study also demonstrate a similar relationship between migration and marriage. Looking at the relationship structure based on the provinces with a significant correlation in the summary table of the LISA map in Table 2, it is reasonable to assume that the reason for migration in these regions is the diversity of employment opportunities in the provinces where migration occurs.

Every $1 \%$ increase in the divorce rate decreases the immigration rate by $18.48 \%$. In examining the relationships between divorce and migration studies, negative relationships were found between divorce rate and migration rate, which supports our study. For example, Akgis (2015) found a negative spatial autocorrelation between these two variables in her study. This can be explained by the loss of welfare and a decrease in income after divorce. The divorced persons' jobs and changing economic conditions make it more difficult for these persons to migrate.

Every $1 \%$ increase in the number of births in the provinces results in a decrease in migration by $0.27 \%$. The increase in the birth rate, like divorce, places an economic burden on families, which affects the decision to migrate. When the effect of birth on migration is considered in terms of provinces with significant correlation in the summary table of the LISA Map in Table 2, and especially in terms of the high-high relationship structure, it is seen that the structure of traditional agricultural activities continues in the majority of these provinces. The existence of such a structure is probably as effective as economic reasons in the inverse relationship between the number of births and migration.

When the amount of honey produced increases by $1 \%$, the migration rate increases by $0.05 \%$. If we look at the beekeeping report of the Ministry of Agriculture and Rural Development Support Institution from 2014', we see that although the number of hives and production volumes has increased annually, the yield has not increased in recent years. Given the decrease in average honey yield per colony in recent years, it can be seen that mobile beekeeping, or, transporting hives from one place to another to obtain more products from a colony of bees and ensure pollination of crops $^{2}$, has been carried out more than in previous years. The route followed in migratory beekeeping passes through provinces where spatial autocorrelation is significant (Izmir, Aydın, Mugla, Kocaeli, Samsun, Trabzon, Adana, Hatay). In addition to explaining the spatial correlation with mobile beekeeping, there is also the possibility that the beekeeper who cannot achieve efficiency despite the increase in

1 (Online) https://www.tkdk.gov.tr/Content/File/Yayin/Rapor/Aricilikv2.pdf

2 (Online) http://www.aricilik.info/aricilik-bilgileri/aricilik/ariciligin-tarihcesi-ve-gelismesi.html 
production volume turns to other sectors. According to the model results, a positive relationship between agricultural areas and migration also supports the relationship between honey production and migration. In recent years, the incentives given in the agricultural sector have increased agricultural mechanization and related structural change. Moreover, the migration rate increases by $0.04 \%$ when the agricultural area increases by $1 \%$ per hectare. With the development of mechanization in agriculture, the demand for labor has also decreased. Thus, it can be seen that one piece of technical agricultural equipment forces an average of 6 agricultural workers to migrate.

A $1 \%$ increase in the number of college and vocational school graduates increases the migration rate by $0.33 \%$. When the results are evaluated on the basis of provinces where spatial autocorrelation is significant, it has been concluded that the main source of income is agriculture and the scarcity of business lines that will benefit from the educated population encourages graduates to migrate in most of these provinces. As stated in the study by Abar (2011), the migration rate of a province increases with the number of educated people in that province.

Each increase in the number of universities increases the given immigration rate by $1.72 \%$. When this result is examined on the basis of provinces with a significant correlation, the increase in the number of universities in these provinces shows that there is an attempt to eliminate a deficiency in education. Despite this, the emigration of individuals in these provinces shows that these schools are not preferred yet due to the fact that the quality of education in new schools has not yet reached the level of education in big cities and the lack of academic staff. As staffing needs are met, and the education system is restructured, the ratio between the number of universities and immigration is expected to reverse in the coming years.

\section{Discussion}

Turkey has seen large waves of migration, especially since the 1950s. Statistical and econometric analysis of the concept of migration in Turkey by domestic and foreign researchers has grown alongside these migration waves. When there is a neighbourhood between the considered units, the research on the phenomenon of migration through spatial econometric techniques used to reveal this relationship structure coincides with research on the 2000s.

Migration studies have shown that in addition to attractive socio-economic factors such as employment, education, and relatives who have already migrated and settled, repulsive factors such as security problems, unemployment, and underdevelopment have an impact on internal migration. In addition, proximity to the area of migration may also have an impact on the decision to migrate. This situation has laid the foundation for the study of the phenomenon of migration using spatial econometric techniques. 
In this study, the factors affecting migration based on provinces (Nuts-3) in Turkey were investigated, the nature of the spatial effect in the data set was determined and an appropriate spatial model was proposed. When the final model results were examined, $\rho$, it was found that the parameter, which is called the spatial autoregression parameter, was significant and positive. This means that the migration rate given for each location is influenced not only by the variables included in the model but also by the given migration in neighbouring locations. To put it more clearly, a high-low migration rate in one region causes high-low migration rates in neighbouring regions.

In order to prevent high migration in sending regions, it is first necessary to eliminate economic differences between cities, develop economic activities that fit the structure of cities, and create suitable work areas for these activities in order to keep qualified personnel in the provinces. The quality of educational investment made in the provinces should be increased, the need for academic personnel in universities should be met, and the student population should be kept in these provinces by structuring education. Efforts should be made to increase productivity in agricultural areas and activities, and the possibility of mechanisation and agricultural credit should be spread so that the entire population engaged in agriculture can access it. In this way, it is expected that income disparities among people in provinces where agriculture is the main source of income will decrease, thus reducing out-migration. However, it should be remembered that the reasons for individuals to migrate may change on a city-by-city basis. Therefore, each city should be considered separately and a policy tailored to that city should be developed. Since migration between provinces in Turkey depends on spatial autoregression, any investment made to minimise migration in one region is likely to have the same effect in neighbouring regions.

Hakem Değerlendirmesi: Dış bağımsız.

Çıkar Çatışması: Yazar çıkar çatışması bildirmemiştir.

Finansal Destek: Yazar bu çalışma için finansal destek almadığını beyan etmiştir.

Peer-review: Externally peer-reviewed.

Conflict of Interest: The author has no conflict of interest to declare.

Grant Support: The author declared that this study has received no financial support.

Authors Contributions: Conception/Design of study: S.T., F.Y.T.; Data Acquisition: S.T., F.Y.T.; Data Analysis/Interpretation: S.T., F.Y.T.; Drafting Manuscript: S.T.; Critical Revision of Manuscript: S.T.; Final Approval and Accountability: S.T., F.Y.T.

\section{References}

Abar, H. (2011). Determinants of Intercity Migration of Turkey: Spatial Econometrics Approach.

Master Thesis, Ataturk University Institute of Social Sciences, Department of Economics.

Anselin, L. (1988). Spatial Econometrics: Methods and Models (Vol. 4). Springer Science \& Business Media. 
Anselin L., Gallo J. L., \& Jayet, H. (2008). Spatial Panel Econometrics. In: Mátyás L., Sevestre P. (eds) The Econometrics of Panel Data. Advanced Studies in Theoretical and Applied Econometrics, vol 46. Springer, Berlin, Heidelberg.

Anselin, L. (2002). Under the Hood İssues in the Specification and Interpretation of Spatial Regression Models. Agricultural Economics, 27(3), 247-267.

Akgis, O. (2015). Spatial Distribution of Happiness as a Well Being Indicator in Turkey. Turkish Geographical Review, 65, 69-76.

Anavatan, A. (2017). Internal Migration and Its Determinants in Turkey: Spatial Data Analysis. Social Sciences Studies Journal (SSSJournal), 9, 1109-1116.

Baltagi, B. H., Egger, P., \& Pfaffermayr, M. (2013). A Generalized Spatial Panel Data Model with Random Effects. Econometric Reviews, 32(5-6), 650-685.

Blommestein, H. J. (1983). Specification and Estimation of Spatial Econometric Models: A Discussion of Alternative Strategies for Spatial Economic Modelling. Regional Science and Urban Economics, 13(2), 251-270.

Cliff, A., \& Ord, J.K. (1972). Testing for Spatial Autocorrelation among Regression Residuals. Geographic Analysis, 4(3), 267-284.

Doh, R. (1984). Inter-provincial Migration in Turkey and its Socio-economic Background: A Correlation Analysis. The Turkish Journal of Population Studies, 6, 49-61.

Elhorst, J. P. (2001). Dynamic Models in Space and Time. Geographical Analysis, 33(2), 119-140.

Elhorst, J. P. (2010). Applied Spatial Econometrics: Raising the Bar. Spatial Economic Analysis, 5(1), 9-28.

Ercilasun, M., Hic Gencer, E. A., \& Ersin, O.O. (2011). Modeling the Determinants of Internal Migration in Turkey. International Conference on Eurasian Economies, (Online) http://avekon. org/papers/378.pdf

Fischer, M.M., \& Wang, J. (2011). Spatial Data Analysis: Models, Methods and Techniques. Springer Science\& Business Media.

Frexedas, O. V., \& Vaya, E. (2005). Financial Contagion Between Economies: An Exploratory Spatial Analysis. Estudios de Economia Aplicada, 23(1), 151- 165.

Geary, R.C. (1954). The Contiguity Ratio and Statistical Mapping. The Incorporated Statistician, 5(3) $1,115-146$.

Getis, A., \& Ord, J.K. (1992). An Analysis of Spatial Association by Use of Distance Statistic. Geographical Analysis, 24(3), 189-206.

Gumprecht, D. (2007). Spatial Methods in Econometrics: An Application to R\&D Spillovers. $W U$ Vienna University of Economics and Business, Doctoral Dissertation, (Online) http://epub. wu.ac.at/290/1/document.pdf

Haining, R. P. (1990). Spatial Data Analysis in the Social and Environmental Sciences. Cambridge University Press.

Hordijk, L. (1979). Problems in Estimating Econometric Relations in Space. Papers in Regional Science, 42(1), 99-115.

Hordijk, L., \& Paelinck, J. (1976). Some Principles and Results in Spatial Econometrics. Recherches Économiques de Louvain/Louvain Economic Review, 42(3), 175-198. 
Lesage, J. P. (1999). The Theory and Practice of Spatial Econometrics. University of Toledo, Ohio.

Munro, J. M. (1974). Migration in Turkey. Economic Development and Cultural Change, 22(4), 634-653.

Ondes, H., \& Ayvaz Kizilgol, O. (2020). Analysis of Factors Affecting Internal Migration in Turkey: Spatial Panel Data Analysis. Business and Economics Research Journal, 11(2), 353-369.

Ozdemir, D. (2018). Determinants of Interregional Internal Migration in Turkey. Ataturk University Journal of Graduate School of Social Sciences, 22(3), 1337-1349.

Ozgur, E. M., \& Aydin, O. (2011). The Evaluation of Marriage Migration Using Spatial Data Analysis Techniques in Turkey. Turkish Journal of Geographical Sciences, 9, 29-40.

Ozkubat, G., \& Selim, S. (2019). Socio-Economic Development of Provinces in Turkey: A Spatial Econometric Analysis. Alphanumeric Journal, 7(2), 449-470.

Paelinck, J. H. (2013). Some Challenges for Spatial Econometricians. Acta Universitatis Lodziensis. Folia Oeconomica, 292, 11-20.

Paelinck, J. H., \& Klaassen, L. H. (1979). Spatial Econometrics, Farnborough: Saxon House.

Pazarlioglu, V. (2007). Econometric Analysis of Internal Migration in İzmir Case. Yönetim ve Ekonomi Dergisi, 14(1), 121-135.

Tunali, I. (1996). Migration and Remigration of Male Household Heads in Turkey 1963-1973. Economic Development and Cultural Change, 45(1), 31-67.

Yakar, M. (2012). Spatial Analysis of Internal Migration by Districts in Turkey: 1995-2000 Period. International Journal of Human Sciences, 9(1),741-768.

Yamak, N., \& Yamak, R. (1999). Türkiye'de Gelir Dağılımı ve İç Göç. Dokuz Eylul University The Journal of Graduate School of Social Sciences, 1(1), 16-28.

Viton, P. A. (2010). Notes on Spatial Econometric Models. City and Regional Planning, 870(3), $1-23$. 